\title{
Challenges to disaster risk reduction: A study of stake- holders' perspectives in Imizamo Yethu, South Africa
}

\author{
Ann-Sofie Roth \\ Dept. of Fire Safety Engineering and Systems Safety, \\ Lund University \\ annsofie.roth@gmail.com
}

Per Becker

Training Regions Research Centre

Lund University Centre for Risk Assessment and Management, Lund University

per.becker@lucram.lu.se

\section{ABSTRACT}

South Africa is a complex and dynamic society, with overwhelming and increasing problems with disaster risk in the vulnerable urban communities in and around its rapidly growing metropolitan centres. The purpose of this study is to improve the understanding of the challenges for disaster risk reduction in such communities. It focuses on the case of Imizamo Yethu, in the Western Cape, in order to build theory that is grounded in the empirical realities of stakeholders involved in disaster risk reduction there. The result points towards five interrelated key challenges, which must be concurrently addressed through large-scale development efforts. Without such investments, it is unlikely that disaster risks can be reduced to tolerable levels.

\section{KEYWORDS}

Disaster risk reduction, development, South Africa, urban, vulnerable, community

\section{Introduction}

South Africa is a dynamic developing country in a challenging transition. The economic purchasing power per person increased more than 173 percent in the first 15 years after Apartheid (World Bank, 2010), while the Human Development Index (HDI) is more or less unchanged since then (UNDP, 2011). South Africa is thus not only one of a few countries in the world that has not experienced human development in this period (Khandlhela \& May, 2006), but this also indicates an overall deterioration in the non-economic indicators of HDI. Next to the mounting impact of HIV/AIDS on life expectancy, this deterioration is mainly caused by policies making a minor part of the population increasingly rich, while the majority becomes increasingly poor. This inequality has obvious roots in Apartheid, but it is important to note that it has been growing ever since. It is in this context that South Africa is struggling to protect life and health, property, infrastructure and the environment from disasters.

It is generally accepted that prevention is better than cure when it comes to disasters (e.g. Davis, 1984; Chafe, 2007; Ki-moon, 2009), and South Africa’s well-developed National 
Disaster Management Act (Act 57 of 2002) and Framework have a strong focus on proactive disaster risk reduction. The country is experiencing rapid urbanisation (UN, 2009), which in the African context generally "is driven by natural growth among already marginalised urban populations and in-migration of the poor" (UNISDR, 2009). The main proportion of the urban growth is thus in unplanned and mostly informal urban settlements, where buildings are of low quality and on land often unsuitable for habitation (UNISDR, 2009). Although South African local government has the responsibility to reduce risk in such urban environments, the task is difficult at best and overwhelming at worst.

Imizamo Yethu, a township in Hout Bay in the Western Cape, illustrates well the complexity and struggle in relation to disaster risk that is the reality in many parts of contemporary South Africa. The settlement was originally designed to accommodate around 3000 people, but now, 20 years later, the exact number of occupants is unknown, ranging from 16 000-36 000 inhabitants. Although Imizamo Yethu has been earmarked for upgrade for over a decade, no substantial improvements have been implemented, while the community faces a wide range of hazards.

The purpose of this study is to improve the understanding of the challenges for disaster risk reduction, within vulnerable South African urban communities, in relation to reoccurring rapid and slow onset disasters, as well as everyday emergencies. To meet that purpose, the study focuses on the case of Imizamo Yethu and intends to answer the following research question:

\section{What challenges to disaster risk reduction are expressed by stakeholders in Imizamo Yethu?}

\section{Methodology and methods}

There may be several research methodologies appropriate for answering the research question. However, Grounded Theory stands out as particularly suitable considering the pragmatic purpose of the study (Wuest, 1995; Hammersley, 2004), as well as the potential complexity of the challenges involved (Glaser, 1992; Wells, 1995). Grounded Theory research begins with an inductive approach, involves simultaneous data collection and analysis, and gives scientific rigour to qualitative research through flexible guidelines (Charmaz, 2006).

This application of Grounded Theory involves qualitative interviews with stakeholders in disaster risk reduction in Imizamo Yethu, i.e. the local chairman of the South Africa National Civic Organization (SANCO, interviewed together with the vice-chairman), the community development worker, a community guide, the health centre of Imizamo Yethu, the fire department of Hout Bay (group interview with a captain and his platoon), the NGO Envirochild, City of Cape Town Disaster Risk Management Centre (group interview with seven managers and experts) and one of the town planners of the city of Cape Town.

Data collection and analysis are interrelated processes in Grounded Theory (Corbin \& Strauss, 1990), meaning that the data are analysed continuously during the data collection. For every interview, the data are analysed by coding segments, identifying concepts by merging codes in and between interviews, and by grouping concepts that include the same phenomenon in categories that are the building blocks of new theory (Charmaz, 2006). In this case, numerous 
codes are merged into 25 concepts, which in turn form five categories that are the building blocks of the constructed grounded theory concerning challenges for disaster risk reduction. For example, many segments of text from the interviews are related to the concept Immigration and migration from the Eastern Cape, which together with the concepts Unregulated rapid settlement growth, Population dynamics and Over crowding, form the category Community growth. The analysis is in other words based on constant comparison of data, concepts and categories (Corbin \& Strauss, 1990).

The final result consists of five categories that together form a grounded theory of the main challenges for disaster risk reduction in Imizamo Yethu. The resulting theory is referred to as grounded in the empirical realities of the people involved, which is crucial in order to link theory and practice, and to facilitate the adoption of the research results into urban disaster risk reduction in Imizamo Yethu and beyond.

\section{Analysing and discussing the empirical findings}

\section{Constructing empirically grounded categories}

To be able to present the analysis and discussion of the empirical findings in a structured way, this section is subdivided according to the resulting five categories. It is important to note that these categories are the end result of the actual Grounded Theory process, and not any preconceived notions.

\section{Community growth}

The rapid and uncontrolled community growth of Imizamo Yethu has resulted in very dense living conditions on land largely unsuitable for habitation, posing multiple risks for the residents. All the participants of the study agree that the overcrowding of the settlement causes a wide range of problems and risks. The community growth causes an increasing strain on the already scarce resources in the township, which is pointed out by one participant to be the main reason for the problems. A majority of the residents in Imizamo Yethu have their roots in the Eastern Cape and it is widely discussed by the participants how people migrate to Cape Town for better employment opportunities, education and service delivery, as well as for medical reasons, e.g. treatment of TB or pregnancy. The on-going migration between the Eastern and Western Cape adds to the already complex and multidimensional risk context. Considering that the site was designed for approximately 3000 residents, and today it is assumed to be home to $16000-36000$ people, community growth is unquestionably a major challenge in terms of risk reduction.

The participants' opinions are conflicting whether the community and/or the city have control over the erection of new dwellings or not. This so called influx control is discussed by most of the participants, and it is widely mentioned that influx control and forced removal of people is a sensitive subject due to South Africa's history of pass laws and forced removal during the Apartheid regime. However, risk and the impacts of disasters multiply when population growth is not met with proper land-use planning and appropriate institutional and legislative arrangements (Marjanovic \& Nimpuno, 2003), and urbanisation is one of the major factors 
that influence the risk level of a nation (Wisner et al., 2004; Coppola, 2007). Imizamo Yethu illustrates well how an unplanned settlement results not only in poor living conditions, but also continues to marginalise its residents.

\section{Lack of land}

There is a consensus among all participants that a lack of land, relative to the number of residents, is a major challenge, both in term of risk reduction and in terms of the proposed upgrade. It is also discussed how the large fire in 2004 changed the settlement dramatically, as it is estimated that approximately 5000 people were left homeless after the event. The city could not find alternative sites for the affected people and the frustration grew. They felt they were being ignored by the city, by not getting land or services and as a result the affected people relocated up the hill. This area is called Dontseyake, meaning un-ruled area, and is characterised by high population density and limited accessibility. The participants discuss the challenges associated with the lack of proper infrastructure, the accessibility within the community, and how the lack of services combined with a high influx pose multiple risks. It is pointed out that it is not only the lack of roads, difficult terrain and the mountain slope that are challenges, e.g. for service delivery, but also the fact that roads become narrowed down or blocked due to the construction of new dwellings and so called 'spaghetti wires' (makeshift electric wires in informal settlements). Even though the fire department is located next to the settlement, it can take up to 30 minutes before the fire fighters can arrive at the top of the settlement, or as one of the fire fighters put it: 'it doesn't matter how much we practise, access is still the biggest challenge'.

Risk accumulation can often be traced to unplanned housing, housing densification, unregulated livelihood activities and a disregard of disaster risk accumulation in urban planning (Pelling, 2007). All these factors can be seen as contributing to the situation in Imizamo Yethu, and although the need for an upgrade has been recognised for a significant time, the lack of new land strongly limits the possibilities to address the situation. The stakeholders all acknowledge the need for development but also add that it would probably require people to move, which most likely would create a conflict situation. How the situation in Imizamo Yethu came to be, and who was to blame, could be discussed ad nauseam. However, the situation clearly shows the importance of land-use planning as a measure to reduce risk.

\section{Politics}

The upgrade of Imizamo Yethu has been an on-going debate for over a decade. This programme is supposed to be the government stakeholder's comprehensive solution to the Imizamo Yethu problem. However, in reality, the process exemplifies the stagnation of the entire situation. The participants mention that conflicting agendas, bureaucracy, disagreements and lack of accountability have meant little has been accomplished. The community residents and leadership are divided, as some residents want all the land to be used for housing, while others want mixed-use development to include community facilities such as schools, community centres and a taxi rank. On a provincial level, conflict between the two biggest political parties (DA and ANC) has contributed to a hold up in the process. Additionally, there are objections 
from neighbouring communities and conservation groups. Several participants point out that the development of the community has unfortunately advanced towards more hazardous areas instead of the opposite.

It should not be forgotten that Imizamo Yethu is filled with people from a range of different cultural backgrounds, and does not necessarily fit the definition of a community. This has according to the participants proven to be a major challenge for accomplishing unity in the township. The participants offer different perspectives on how the upgrading process is held up. Although they voice different opinions of what would be best for the community, they agree that the conflicting agendas, both between the community residents and with the neighbours, pose a major challenge. As previously stated, discussing the reasons why and how Imizamo Yethu came to be what it is today could go on ad infinitum. What was initially planned to be an opportunity for the original residents turned instead into a highly hazardous living situation. Even though root causes of the risks in Imizamo Yethu seem to be understood, the treatment of them is highly polemical. This is no surprise, as it has been suggested that such activities are always political (Wisner et al., 2004:61).

\section{Institutional capacity}

The definition of disaster and the view on the ongoing disaster risk management in Imizamo Yethu differ between participants, but they all agree that the lack of human and financial resources to implement the objectives of the Act, as well as to address the daily needs of the residents, is a major challenge to disaster risk reduction. The National Disaster Management Act states that an event is a disaster if it 'is of a magnitude that exceeds the ability of those affected by the disaster to cope with its effects using only their own resources'. However, the participants disagree on whether or not certain events are disasters or not. Regardless of this, each event is a setback in the sense that it keeps people in a vulnerable state until the next event strikes. These recurrent setbacks, in combination with the lack of resources to provide housing and services, are viewed by the participants as causing a stagnant situation with limited chances to develop the community. The participants from the community state that city officials are often unable to help out and deliver what the residents think they are entitled to. Whether this is due to lack of knowledge, resources or will, it could be argued that inefficient city offices pose as much of a challenge to risk reduction in Imizamo Yethu as any structural challenges.

The National Disaster Management Act declares that disaster mitigation is a 'multi-sectoral, multi-disciplinary process of planning and implementation'. Unless all involved stakeholders are working towards the same goal, within an organised coordinated framework, and are aware of their roles and responsibilities, improvements will be difficult to achieve. Vermaak and Van Niekerk (2004) point out that one of the main challenges for disaster risk reduction is to find 'effective means, a comprehensive and multi-sectoral approach, to reduce risk through professional disciplines as well as public participation' and they conclude that this requires both political and public commitment as well as an understanding on local community level. Advanced legislation shows a will to achieve a certain standard but it needs to be followed with education and skills training to achieve the set goals and to fully implement the aims and goals. 
The Act is a very advanced piece of legislation and, as one of the participants points out, it could be described as a 'westernised' Act. South Africa's context is very complex in the sense that it comprises issues associated with so-called 'first world' countries, as well as 'third world' countries. Implementing such a 'westernised Act' in the less developed parts of South Africa may be very difficult (Martin et al., 2002).

\section{Community risk behaviour}

Human behaviour is mentioned by many participants as playing an essential part in the progression of risk in the community. The participants share different theories as to why people put themselves in hazardous positions, ranging from desperation to strategic motivations caused by lack of education, lack of consideration or lack of options. One of the challenges all stakeholders express is the lack of understanding among the community residents that there is no space left for housing - as soon as one area opens up, e.g. to provide services, it get filled with new dwellings instantly. The problems with the lack of sanitation facilities and people's habit of using the hillside as a public toilet are also discussed. Additionally, fires are mentioned as a massive problem in Imizamo Yethu, and it is argued that the consequences of fires would be less devastating if dwellings were built a certain distance apart and/or not on top of fire hydrants, and if roads were kept clear. Another considerable issue that is mentioned is the number of informal dwellings constructed on top of the pipe leading from the water reservoir of Hout Bay, located on the top of the settlement. These constructions make it impossible to monitor and do repairs on the pipe and have also become a political dispute in view of the court order to remove the dwellings.

Basic infrastructure and land use planning are crucial to address risks, but risk reduction efforts also need to have an educational focus so that people are able to take responsibility for their own situation. However, at this point, the lack of space and resources limits the residents' opportunities to improve their situation. It should also be noted that if a community is struggling with day-to-day challenges, disaster risks are unlikely to be considered important and long-term perspectives are not necessarily a part of their decision-making process. Risks that are considered acceptable are not necessarily reflecting the actual risk level, but the subjective determination (Coburn et al., 1994). Disaster risk reduction requires ownership from not only the officials but also people living within the community. If people feel that they have little control over the situation, it often results in undermining their attempts to reduce the risks impacting on their day-to-day life (Nomdo \& Coetzee, 2002). Some risk behaviour by the community can also be viewed as vain attempts to address the challenges themselves, where they consider the authorities have not delivered. Without alternative solutions being given to people, or the tools to improve the situation in a way that complies with the rules of a society, people are forced to sit and wait for the different spheres of government to address the problems.

\section{A grounded theory of challenges for urban disaster risk reduction in South Africa}

The challenges to disaster risk reduction in Imizamo Yethu are complex and related to each other in such a way that it is futile to address one in isolation. In grasping this complexity, it 
may be helpful to view each of the five key challenges as sides of an open box (Figure 1). At the bottom of the box is Community growth, which is enclosed by the other four challenges. As the community grows, it hits wall after wall in attempts to address its situation and eventually becomes boxed in and unable to reduce its risks. In addition to Community growth, which is connected to all the others, Politics is closely connected to Institutional capacity and Lack of land, which in turn are connected to Community risk behaviour (Figure 1). As the population pours in, each side of the box must be concurrently addressed in order for the box to hold as the pressure increases.

Figure 1:The box analogy as an overview of the challenges for disaster risk reduction in Imizamo Yethu.
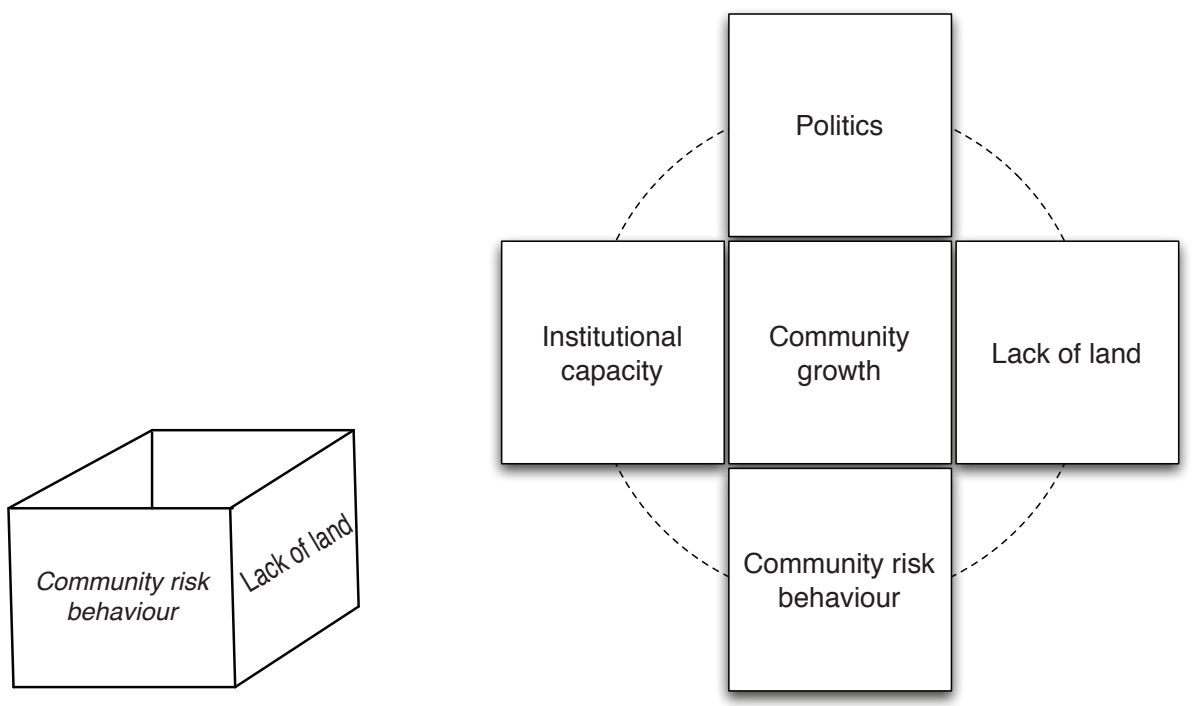

Source: Compiled by Author

\section{Conclusion}

So, what challenges to disaster risk reduction are expressed by stakeholders in Imizamo Yethu? In many ways Imizamo Yethu illustrates how disaster risk is a complex mix of environmental processes and human actions. The main challenges for disaster risk reduction expressed by the involved stakeholders are:

Community growth - the uncontrolled growth and the overcrowding of the community are viewed as a major challenge as they cause multiple risks for the residents and increase their vulnerabilities. Such growth is also seen as a challenge in terms of relocating people due to the history of South Africa and its previous forced removals.

Lack of land - the overcrowding of the area results in use of land largely unsuitable for habitation and the limited space combined with a rapid growth results in an unplanned settlement. The lack of land is seen as a challenge as it limits the ability to address the identified hazards through prevention and mitigation measures, and also the ability to respond to rapid onset disasters. 
Politics - the upgrade process, initiated to address the problems in the settlement, is seen as another considerable challenge due to conflicting development agendas, disagreements within the settlement, objections from outside stakeholders, and political disputes.

Institutional capacity - the lack of institutional capacity to provide housing and service deliveries is considered a major challenge. The definition of disaster and the view on ongoing disaster risk reduction initiatives in Imizamo Yethu differ between stakeholders, but the common point is the lack of resources to implement the objectives of the Act, as well as the lack of human and financial resources to address the daily needs of the residents.

Community risk behaviour - understanding and ownership of risk among the community residents is considered another challenge. In addition to battling over a lack of land, Imizamo Yethu also struggles with the fact that human behaviour puts people and the environment at risk daily.

These five categories, the sides of the box presented in the previous section, depend on and determine each other in such a way that it is futile to attempt to deal with one in isolation. At the very bottom of the box is the rapid inflow of people into a fixed and static space, like water flowing in. Eventually the box will be full and the pressure will break the box. Addressing this apocalyptic scenario, which may not be far away for Imizamo Yethu, requires massive development initiatives to be implemented. Not only in and around the township itself, but also in the Eastern Cape to reduce the socio-economic gravitation towards the Western Cape that drives people to migrate. However, the already high population density must also be addressed, either by allocating more land, build multi-story buildings or presenting an alternative location that is attractive enough for inhabitants to choose to move. The political deadlock around the future of Imizamo Yethu must in other words be solved, which obviously is easier said than done, especially as large public investments are necessary to have capacity to meet the needs for housing and service deliveries in the township. Finally, large-scale public awareness raising campaigns are needed to address various and widespread behaviours and activities that increase risk in the community.

South Africa may have one of the most sophisticated policy frameworks for disaster risk reduction in the world, but its implementation is difficult in a situation where the identified challenges require such fundamental developmental changes. Hence, this study shows yet again that disaster risk reduction is a development problem and must be an integrated part in development planning. Although this study focuses on the challenges for disaster risk reduction in Imizamo Yethu, it is likely that the complex challenges facing this particular township are common to most townships in and around Cape Town and other rapidly growing large urban centres in South Africa. If so, the result of the study gives further backing to already established ideas that all administrative levels and sectors of government in South Africa must start pulling in the same direction. A direction towards not only economic growth, but towards sustainable development in which the government must dare to formulate long-term strategies for how to facilitate viable livelihoods and attractive living conditions in other locations than the large urban South African metropoles. 


\section{References}

CHAFE, Z. 2007. Reducing natural disaster risk in cities. (In Worldwatch Institute, ed. State of the world 2007: our urban future. London: Earthscan. pp. 112-133.)

CHARMAZ, K. 2006. Constructing grounded theory: a practical guide through qualitative analysis. London: Sage. 224 p.

COBURN, A.W., SPENCE, R.J.S. \& POMONIS, A. 1994. Vulnerability and Risk Assessment. Geneva: UNDisaster Management Training Programme.

COPPOLA, D.P. 2007. Introduction to international disaster management. Oxford: ButterworthHeinemann. 576 p.

CORBIN, J.M. \& STRAUSS, A.1990. Grounded theory research: procedures, canons, and evaluative criteria. Qualitative sociology, 13(1):3-21.

DAVIS, I.R. 1984. Disaster mitigation: prevention is better than cure. Reading Development Communications Bulletin, 18, Oct. Reading: University of Reading.

GLASER, B.G. 1992. Emergence vs forcing: basics of grounded theory analysis. California: Sociology Press. 129 p.

HAMMERSLEY, M. 2004. The dilemma of qualitative method: Herbert Blumer and the Chicago tradition. London: Routledge. 271 p.

KHANDLHELA, M. \& MAY, J. 2006. Poverty, vulnerability and the impact of flooding in the Limpopo Province, South Africa. Natural hazards, 39(2):275-287.

KI-MOON, B. 2009. Building disaster risk reduction capacities crucial as vulnerability grows, secretary-general emphasizes at opening of office, training centre. New York: United Nations. Available at http://www.un.org/News/Press/docs/2009/sgsm12409.doc.htm

MARJANOVIC, P. \& NIMPUNO, K. 2003. Living with risk: toward effective disaster management training in Africa. (In Kreimer, A., Arnold, M. \& Carlin, A., eds. Building safer cities: The future of disaster risk. Washnington D.C.: World Bank. pp. 197-209.)

MARTIN, B., CAPRA, M.F., VAN DER HEIDE, G., STONEHAM, M.J. \& LUCAS, M. 2002. Are disaster management concepts relevant in developing countries? The case of the 1999-2000 Mozambican floods. Australian Journal of Emergency Management, 16(4):25-33.

NOMDO, C. \& COETZEE, E. 2002. Urban vulnerability: perspectives from Southern Africa. Cape Town: Periperi Publications. 220 p.

PELLING, M. 2007. Investigating urban risk accumulation in six countries in Africa. Cape Town: African Urban Risk Analysis Network.

UN (United Nations). 2009. World urbanization prospects: the 2009 revision. Available at: http://esa. un.org/unpd/wup Date of access: 1 Apr. 2011.

UNDP (United Nations Development Programme). 2011. HDI trend for South Africa 1990-2010. Available at: http://hdr.undp.org Date of access: 31 Mar. 2011.

UNISDR (United Nations International Strategy for Disaster Reduction). 2009. Status report on disaster risk reduction in sub-Saharan Africa - contributing to the implementation of the Hyogo Framework 
for Action and the Africa Regional Strategy. Nairobi: UNISDR Regional Office for African in collaboration with The African Union Commission and The World Bank - GFDRR.

VERMAAK, J. \& VAN NIEKERK, D. 2004. Disaster risk reduction initiatives in South Africa. Development Southern Africa, 21(3):555-574.

WELLS, K. 1995. The strategy of grounded theory: possibilities and problems. Social work research, 19(1):33-37, Mar.

WISNER, B., BLAIKIE, P.M., CANNON, T. \& DAVIS, I. 2004. At risk: natural hazards, people's vulnerability and disasters. 2nd ed. London: Routledge.

WORLD BANK. 2010. Economic policy and external debt. Available at: http://data.worldbank.org/ topic/economic-policy-and-external-debt Date of access: 8 Feb. 2011.

WUEST, J. 1995. Feminist grounded theory: an exploration of the congruency and tensions between two traditions in knowledge discovery. Qualitative Health Research, 5(1):125-137, Feb. 